\title{
Reseña del libro "Reflexiones sobre investigación artística e investigación educativa basada en las artes”.
}

\author{
María Lorena Cueva Ramírez \\ Graduada en Bellas Artes por la \\ Universidad de Granada \\ Doctoranda en el Programa de \\ Patrimonio de la Universidad de Jaén \\ España \\ lorenacue14@gmail.com
}

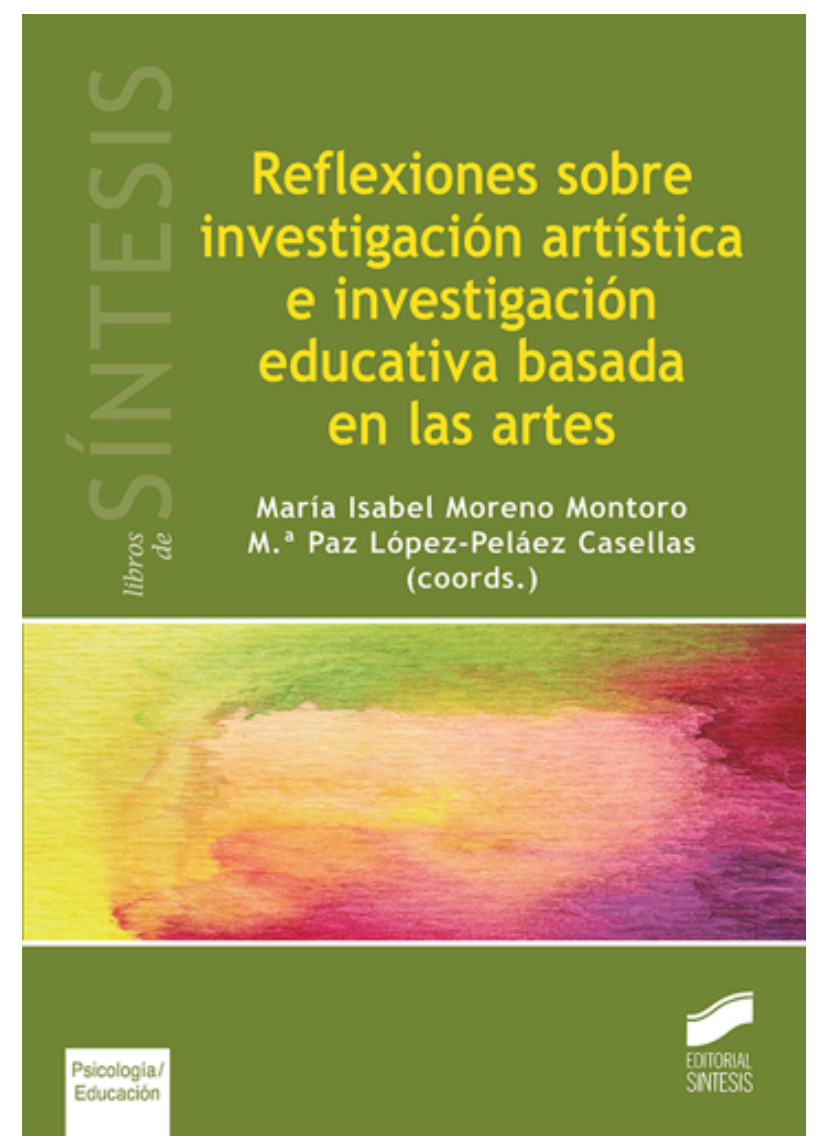

Revisado 10/06/2017

Publicado 01/07/2017

\section{Reflexiones sobre investigación artística e investigación educativa basada en las artes}

Moreno Montoro, María Isabel · López-Peláez Casellas, M. ${ }^{a} \mathrm{Paz}$ (coordinadoras)

Publicado: 15.12.2016

Páginas 184

ISBN: 9788490774458

ISBN Digital: 9788490779767

Editorial Síntesis

\section{Sugerencia para citar este artículo}

Cueva Ramírez, M.L. (2017). Reseña del libro "Reflexiones sobre investigación artística e investigación educativa basada en las artes”. Tercio Creciente, 12, págs. 121-126.

DOI: $10.17561 /$ rtc.n12.9 
DOI: 10.17561/rtc.n12.9

Reseña de libro
http://revistaselectronicas.ujaen.es/index.php/RTC/index www.terciocreciente.com

Palabras clave / Keywords

Investigación Artística, Investigación Educativa Basada en las Artes, Conocimiento Artístico/

Arts Research, Arts-based Educational Research, Artistic Knowledge

\section{Sugerencia para citar este artículo}

Cueva Ramírez, M.L. (2017). Reseña del libro "Reflexiones sobre investigación artística e investigación educativa basada en las artes”. Tercio Creciente, 12, págs.121-126.

DOI: $10.17561 /$ rtc.n12.9 


\section{Reseña del libro "Reflexiones sobre investigación artística e investigación educativa basada en las artes”.}

Sin duda este es un libro que puede llamar la atención de aquellas personas interesadas o implicadas en el arte. Se trata de un libro enmarcado en el ámbito artístico, educativo e investigativo. En él encontramos experiencias personales, reflexiones y pensamientos de profesionales que se desarrollan en los campos de la investigación universitaria, museos y organismos culturales, los cuales abordan no sólo el "qué” o el “cuándo”, sino también “cómo es el arte”.

El contexto del que surge esta propuesta es el Máster Oficial en Investigación y Educación Estética: Artes, Música y Diseño, en la Universidad de Jaén. Un espacio de aprendizaje en el que surgen diálogos, intercambio de ideas y experiencias, debates.

Los que nos dedicamos a cualquiera de las prácticas artísticas somos conscientes del factor azaroso que conlleva su aprendizaje y enseñanza. Aspecto que ha de trasladarse a la investigación en Educación Artística, ya que investigar supone hacer el esfuerzo de intentar entender, formulando preguntas y buscando sus respuestas.
Evidentemente, en Educación Artística también es necesario hacer una revisión continua de los conocimientos establecidos. Podemos decir que la aportación más importante que nos ofrece el proceso de investigación en educación artística es el hecho de identificar problemas y cuestiones y recopilar información, lo que nos permite crear nuevos modelos y estrategias para enriquecer el conocimiento.

De esta manera, el libro nos ofrece una aproximación desde diferentes recorridos a las cuestiones que nos llevan a la búsqueda de nuevas formas de indagación basadas en la práctica artística desde diferentes enfoques como es el caso de la Investigación artística siendo el proceso y resultado de la investigación la misma producción artística o de la Investigación Basada en las Artes, donde la creación artística constituye el método o herramienta para la obtención de la información o datos de nuestra investigación. Así, desde esta perspectiva, el libro pretende ser un guiño hacia el encuentro con nuevas formas de indagación basada en la actividad artística con la intención de que emerjan acciones 
que den cuenta de la experiencia vivida. Por tanto, desde la naturaleza flexible, dinámica e intersubjetiva y el carácter relacional que propone el proceso creativo, se abren nuevos significados como forma de investigación, visibilizando cuestiones que no podrían mostrarse de otra forma. Así, la investigación artística está atenta a nuevos aspectos de la vida donde cada representación no aparece de forma aislada, sino más bien, formando parte de un todo en esa unión entre arte-vida que se establece a través del carácter relacional que ofrecen las artes. Esto nos lleva al encuentro con la a/r/ tografía, una investigación que tiene lugar en contextos educativos como acción colectiva entre los sujetos que participan y desde la creación artística como producto de la investigación con la comunidad, reflexionando a partir del proceso común desarrollado por los agentes implicados en la acción. Tomando este enfoque de investigación, encontramos una gran variedad de aportaciones según las experiencias de investigación vividas por cada una de las autoras y autores que participan, dando lugar a una amplia mirada desde sus prácticas y mostrando así, nuevas formas de acción socioeducativa derivada del proceso creativo donde se ven implicados, al mismo tiempo que funcionan como ejemplos de intervención artística en diferentes contextos educativos.

En los último años han surgido nuevas disciplinas a partir de la agrupación de la práctica artística, docente y la especulación teórica, a las que nos referimos a través de los conceptos investigación artística, investigación basada en las artes o investigación educativa basada en las artes. Conceptos que buscan adaptar la educación artística a las estructuras cada vez más homogéneas a nivel mundial, que están siendo marcadas por el sistema educativo superior.

Este libro quiere dar lugar a un diálogo productivo con el objetivo de profundizar en el concepto de investigación artística, nuevas maneras de tratar la vinculación entre arte, educación y profesionalización.

$Y$ es que, actualmente, contamos con una cantidad enorme de profesionales que tienen la disposición de dar una vuelta de hija a la educación, que quieren innovar con ideas creativas. Con estas nuevas propuestas y el trabajo en conjunto se puede crear la educación que necesitamos en el presente y que nos llevará a la del futuro. 
Tabla de contenidos del libro:

Prólogo.

Como pretexto para pensar en voz alta.

Teresa Torres de Eça y M. ${ }^{a}$ Jesús Agra Pardiñas

Parte I. Situando un marco de conocimiento y procedimiento

1. La investigación para el conocimiento artístico ¿Una cuestión gnoseológica o metodológica?

María Isabel Moreno Montoro, María Guadalupe Valladares González y María Martínez Morales

2. Prácticas cualitativas para la investigación sobre las artes.

Pedro Jesús Luque Ramos y Carmen María Cruz Elvira

3. Desterritorialización: de la academia a la cocina, si de investigación se trata.

Giselda Hernández Ramírez

Parte II. Conviviendo con el sistema educativo

4. Aprender en las artes y a través de ellas: cooperaciones, integración del currículo y evaluación de programas.

Mary Hafeli y Harold Abeles

5. Cartografías multisensoriales en educación. Una propuesta desde el aula de música.

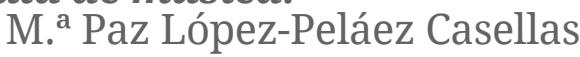


Parte III. Supervivencia a pesar del sistema

6. Conclusiones para entender el fracaso social de la gestión artística etnocéntrica.

Ana Tirado de la Chica

7. Explorar las características culturales de hacer arte para la justicia social.

Marit Dewhurst

8. Educación estética, creación y retos sociales.

María Dolores Callejón-Chinchilla

9. ¿Qué es la crítica? Arte, pensamiento y verdad. José-Luis Anta Félez 